\title{
DOCUMENTO
}

\section{DECLARACIÓN CONJUNTA \\ CHILE-BRASIL}

Accediendo a una invitación del Ministro de Relaciones Exteriores de Chile, Don Enrique Silva Cimma, el Ministro de Relaciones Exteriores de la República Federativa del Brasil, Don Fernando Henrique Cardoso, realizó una Visita Oficial a Chile entre los días 23 al 27 de marzo de 1993. El señor Canciller del Brasil estuvo acompañado de su señora Ruth Cardoso y de una comitiva de alto nivel.

Durante el desarrollo de la visita oficial, el Ministro de Relaciones Exteriores de Brasil fue recibido por S.E. el Presidente de la República de Chile, Don Patricio Aylwin Azócar. En dicho encuentro, el Jefe de Estado extendió una invitación a S.E. el Presidente de la República Federativa del Brasil, Don Itamar Franco, para que visite oficialmente Chile durante el transcurso del presente año.

El Ministro Cardoso también se entrevistó con el Presidente del Senado, Don Gabriel Valdés Subercaseaux; el Presidente de la Cámara de Diputados, Don José Antonio Viera-Gallo y con los Ministros de Relaciones Exteriores, Don Enrique Silva Cimma; de Economía, Don Jorge Marshall; de Hacienda, Don Alejandro Foxley; Secretario General de Gobierno, Don Enrique Correa y Secretario General de la Presidencia, Don Edgardo Boeninger.

El Ministro de Relaciones Exteriores del Brasil, en compañía del Alcalde de la Ilustre Municipalidad de Santiago, Don Jaime Ravinet, procedió a inaugurar un busto del patrono de la diplomacia brasileña, el Barón de Río Branco, ubicado en la intersección de las Avenidas Brasil y Libertador Bernardo O’Higgins.

El Ministro visitante fue condecorado por el Ministro de Relaciones Exteriores de Chile con la Gran Cruz de la Orden al Mérito.

Por su parte, el Ministro Silva Cimma fue condecorado por el Ministro Cardoso con la Gran Cruz de la Orden de Río Branco.

El Ministro Cardoso pronunció una Conferencia, patrocinada por la Academia Diplomática de Chile, sobre el tema "Desarrollo e Integración: Respuestas a un Nuevo Contexto Internacional". 
El Rector de la Universidad de Chile, en ceremonia efectuada en el Salón de Honor, confirió al Ministro visitante el título de "Doctor Honoris Causa" de esa institución de estudios superiores.

Durante sus conversaciones, ambos Ministros analizaron la situación internacional y regional e intercambiaron puntos de vista sobre el estado de la vinculación entre los dos países en lás esferas política, económica, social y cultural. Junto con reafirmar la voluntad política de sus respectivos gobiernos de continuar desarrollando acciones tendientes a fortalecer el entendimiento recíproco en dichas áreas, convinieron en la siguiente Declaración Conjunta que registra las coincidencias entre ambos gobiernos:

\section{Fortalecimiento de las relaciones bilaterales.}

1. Consideraron, en primer término, el marco global en que las relaciones se desarrollan y se felicitaron por la tradición de estrecha amistad y amplia cooperación que ha caracterizado históricamente a la vinculación entre Chile y Brasil desde que ambos países establecieron relaciones diplomáticas en 1836 . Al respecto, señalaron su convicción de que la profundización de esa relación representa una efectiva contribución para la paz y la solidaridad de la región en su conjunto. Manifestaron, igualmente, su convicción más decidida en mantener las relaciones bilaterales en los más altos niveles de excelencia.

2. Comprobaron que, en los últimos años, Chile y Brasil han recorrido caminos semejantes en los procesos de transición política hacia la democracia y de consolidación de sus instituciones, proceso que ha derivado exitosamente en el afianzamiento del régimen democrático, de las libertades individuales, del respeto a los derechos de las personas, así como en el crecimiento económico y el desarrollo social con equidad.

3. Destacaron la importancia significativa del intercambio comercial entre los dos países. Reafirmaron la determinación de ambos gobiernos por explorar conjuntamente fórmulas que permitan lograr un aumento y liberalización de los flujos comerciales, procurando la máxima apertura de los respectivos mercados. Asimismo, los Ministros coincidieron en la conveniencia de intensificar los vínculos y la 
cooperación económica entre ambos países y de suscribir un Protocolo para la constitución de un Consejo Bilateral de Economía y Comercio que sirva de marco para profundizar las relaciones económicas y el comercio bilateral. Dicho Consejo estará encargado, entre otras materias, de estudiar la negociación de un Acuerdo de Complementación Económica.

4. Reiteraron lo expresado por los Presidentes de Chile y Brasil, en la Declaración Conjunta de Brasilia de 1990, en el sentido de impulsar el estudio y formulación de proyectos para materializar la interconexión rodo-ferroviaria que unirá los océanos Pacífico y Atlántico. En este sentido acordaron intercambiar Notas Reversales destinadas a formalizar la constitución de una Comisión Técnica Bilateral, que se encargará de estudiar el tema y formular las propuestas correspondientes. Ambos países conceden gran importancia al viaje promocional que efectuará un tren especial entre los puertos de Antofagasta y Santos, a partir del 14 de abril próximo.

5. Reconocieron la importancia y utilidad de los contactos establecidos entre ambas Cancillerías a través del actual Mecanismo de Consultas Permanentes al que resolvieron respaldar de la manera más plena y decidida. Ambos Cancilleres coincidieron en identificar tal instrumento como el medio más efectivo para evaluar periódicamente los avances de la relación bilateral y para colaborar con la paz, la seguridad y la integración hemisférica.

6. Señalaron su más entusiasta reconocimiento y apoyo al "Seminario Chile-Brasil en la década de los noventa", organizado por el Instituto de Estudios Internacionales de la Universidad de Chile y realizado en Santiago en 1991, así como a la continuación de ese evento, que se efectuará en Brasil, con el patrocinio de la Fundación Simonsen de la Federación de Industrias del Estado de São Paulo. Constataron que este tipo de seminarios y encuentros contribuye efectivamente al mejor conocimiento recíproco y a la búsqueda de ideas que posibiliten auscultar nuevas áreas para la relación bilateral.

7. Expresaron su satisfacción por los logros alcanzados entre Chile y Brasil en materias de cooperación técnica, científica e intercambio cultural y académico, que se han dinamizado con la ejecución de los 
respectivos acuerdos y cuya manifestación práctica se expresa en los programas de acción acordados en esta oportunidad.

8. Destacaron el interés de la Academia Diplomática de Chile y del Instituto Río Branco por establecer un mecanismo de cooperación mutua, que incluirá el intercambio de visitas de nivel directivo, de profesores visitantes en ambas instituciones académicas para dictar cursos específicos y de alumnos que puedan asistir a un período de estudio válido para el curriculum en ambas instituciones. Ambos Ministros expresaron su decidido apoyo a esta materia.

9. Registraron, con satisfacción, el notable incremento de la cooperación entre universidades brasileras y chilenas, el aumento del intercambio académico y la gran cantidad de proyectos conjuntos en el área de enseñanza superior. Señalan que tales iniciativas siguen fructificando y que otros acuerdos de cooperación inter-universitaria están en vías de concretarse.

10. Manifestaron su gran interés en el desarrollo de este tipo de actividades, reconociendo, al mismo tiempo, la autonomía de las instituciones de enseñanza superior de los dos países para establecer sus programas de intercambio y cooperación

11. En este contexto, tomaron conocimiento de las negociaciones en curso para la concreción de los cuatro proyectos de cooperación en el área universitaria que se indican: mico;

a) Intercambio de experiencias sobre reconocimiento acadé-

b) intercambio de experiencias sobre formulación de investigación científica;

c) creación de cátedra de estudios brasileros; y

d) edición de textos académicos de autores de los dos países.

12. Expresaron su satisfacción por los trabajos de la Comisión Mixta Cultural Brasil-Chile, cuya I reunión tuvo lugar en Santiago, en junio de 1990, y manifestaron el deseo que la II reunión se realice en breve, con el propósito de elaborar un programa de trabajo de cooperación cultural bilateral, en el cual se contemple, entre otras actividades, la realización de un Encuentro Universitario Brasil-Chile. 
13. Hicieron presente su complacencia por las diversas iniciativas conjuntas surgidas en estos días y por la suscripción en esta oportunidad de los siguientes documentos:

a) Protocolo para la constitución de un Consejo Bilateral de Comercio e Inversión.

b) Intercambio de Notas destinadas a formalizar constitución de Comisión Técnica Bilateral para elaborar estudios técnicos respecto a conexión océanos Atlántico y Pacífico.

c) Convenio de Cooperación Turística.

d) Acuerdo sobre el Ejercicio de Actividades Remuneradas por parte de Dependientes del Personal Diplomático, Consular y Administrativo y Técnico.

Protocolos Complementarios al Acuerdo Básico de Cooperación Técnica, Científica y Tecnológica entre la República de Chile y la República Federativa del Brasil, relativos a:

e) Programa de Acción 1993-94 en Materia de Cooperación Técnica;

f) Programa de Cooperación Bilateral en el Area Espacial; y

g) Bases de Cooperación entre el Ministerio de Planificación y Cooperación de Chile (MIDEPLAN) y el Instituto de Pesquisa Económica Aplicada del Brasil (IPEA).

14. Expresaron su complacencia por la constitución del Comité Empresarial Chile-Brasil por parte de empresarios de ambos países, pertenecientes a la Confederación de la Producción y del Comercio de Chile y el Consejo Empresarial Permanente del Ministerio de Relaciones Exteriores del Brasil.

\section{Cooperación regional.}

15. Reiteraron su convicción en la plena vigencia del mecanismo de consulta y concertación política institucionalizado en el Grupo de Río. En este sentido, comprobaron la notable eficacia y validez de tal instrumento que está permitiendo analizar mancomunadamente los problemas de mayor relevancia que afectan a nuestro continente y a la vez, se ha constituido en interlocutor con otras importantes instancias del quehacer internacional, como ocurre con el diálogo que se está desarrollando con la Comunidad Económica Europea y con otros países o grupos de naciones. Asimismo, manifestaron su deci- 
sión de trabajar mancomunadamente en la preparación de la Reunión Cumbre Presidencial que se realizará en Santiago, en octubre próximo.

16. Reafirmaron su voluntad de continuar desplegando ésfuerzos con miras a procurar que tenga éxito la tarea que está desarrollando la Misión Civil oNU/OEA en Haití. A tal efecto, reiteraron su apoyo a todas las iniciativas que han impulsado a la Organización de Estados Americanos y la Organización de Naciones Unidas para restablecer la institucionalidad democrática y la plena vigencia de los derechos humanos en ese país.

17. Dejaron expresa constancia de su más decidido respaldo a las Cumbres Iberoamericanas realizadas en Guadalajara y Madrid. Ratificaron su firme adhesión al "Documento de Conclusiones" firmado en Madrid el 24 de julio en la Segunda Reunión de Cumbre Iberoamericana. Asimismo, expresaron su firme propósito de cooperar para el éxito de la Tercera Cumbre que se llevará a cabo en Brasil, durante el presente año.

18. Destacaron la trascendencia del Parlamento Latinoamericano, el que constituye un valioso medio en la perspectiva de la integración y solidaridad regionales, congratulándose porque Brasil sea la sede permanente de esa institución.

19. Reiteraron su satisfacción por la adopción de las enmiendas al Tratado para la Proscripción de las Armas Nucleares en América Latina (Tlatelolco) que fueron propuestas por Chile, Brasil y Argentina, a fin de avanzar hacia la plena vigencia de dicho instrumento; $y$ destacaron los pasos dados por los tres países para consolidar la desnuclearización de la región.

20. Reconociendo la importancia de las tecnologías espaciales para el desarrollo de los países y la investigación del cambio global, resoivieron prestar su decidido apoyo a la II Conferencia Espacial de las Américas que se celebrará en Santiago, Chile, del 26 al 30 de abril de 1993. El Gobierno del Brasil se hará representar en dicha reunión por autoridades del más alto nivel. 


\section{Concertación en el plano internacional.}

21. Expresaron su renovada adhesión a los principios y disposiciones consagrados en la Carta de Naciones Unidas y de la Organización de Estados Americanos. Asimismo manifestaron su decisión de fortalecer los mecanismos e instrumentos que aseguran el mantenimiento de la paz y seguridad internacionales.

22. Manifestaron su firme adhesión a las instituciones democráticas, a la plena vigencia de las libertades fundamentales y al respeto a los derechos humanos. En este sentido expresaron su satisfacción por la estrecha solidaridad que ha surgido frente a los frustrados intentos de alterar la institucionalidad en el continente.

23. Expresaron su satisfacción por los resultados de la Conferencia de Naciones Unidas sobre el Medio Ambiente y el Desarrollo, incluyendo la adopción de la Declaración de Río y la firma de las Convenciones sobre Biodiversidad y Cambio Climático; y confirmaron su decisión de trabajar activamente en la ejecución de los programas de la Agenda 21.

Convinieron en que, para poner en práctica los acuerdos de la Conferencia de Río y los procesos de desarrollo sustentable que se deriven de ellos, es necesario que los programas económicos y sociales, así como aquéllos de protección y conservación ambiental de los países en desarrollo, cuenten con los aportes tecnológicos ambientalmente apropiados y recursos financieros adicionales.

24. Reafirmaron la importancia que ambos gobiernos atribuyen a los esfuerzos de liberalización del comercio internacional y, en tal sentido, otorgan su respaldo a las negociaciones de la Ronda Uruguay en el marco del GATT, cuya conclusión positiva permitirá el fortalecimiento de la economía mundial y hará viable nuevas oportunidades para el crecimiento de las economías de los países en desarrollo.

25. Confirmaron la decisión de ambos gobiernos de apoyar, tanto en el campo bilateral como en el multilateral, los trabajos preparatorios de la Cumbre Mundial de Desarrollo Social, convocada para 1995 por la Asamblea General de Naciones Unidas. 
26. Tomando nota de la suscripción en el pasado mes de enero en París de la Convención sobre la Prohibición del Desarrollo, la Producción, el Almacenamiento y el Empleo de Armas Químicas y sobre su Destrucción, renovaron la intención expresada en el "Compromiso de Mendoza" de contribuir activamente a la proscripción tọtal de las armas de destrucción masiva, tanto a escala global como regional.

Por otra parte, el Gobierno de Chile invitó al Gobierno de Brasil a participar en el Seminario Regional de Armas Químicas, que se realizará el 6 y 7 de septiembre próximo en la ciudad de Viña del Mar, destinado a difundir los derechos, obligaciones y alcances de la Convención sobre Armas Químicas.

27. Acordaron concertar sus posiciones en la Conferencia de las Naciones Unidas sobre Pesca en Alta Mar, a fin de lograr un régimen efectivo de conservación de los recursos vivos marinos, que contemple el interés especial del Estado costero en las especies que se encuentran en aguas adyacentes a su Zona Económica Exclusiva.

28. Resolvieron asimismo acentuar su cooperación en los foros del Sistema del Tratado Antártico, manteniendo una estrecha consulta acerca de las negociaciones para el establecimiento de una Secretaría del Tratado Antártico y del perfeccionamiento de la protección ambiental en dicho continente.

Acordaron intensificar la cooperación científica antártica y la investigación oceánica, para lo cual dispusieron la convocatoria a una reunión de los organismos responsables de los respectivos programas científicos.

29. Se congratularon por el apoyo mutuo brindado a las diversas candidaturas presentadas por los dos países en Organismos Internacionales que reflejan el alto nivel de entendimiento y cooperación alcanzado entre ambas Cancillerías.

30. Destacaron la importancia que reviste la candidatura del señor Rafael Moreno a la Dirección General de la FAÓ, resaltando que ésta cuenta con el sólido respaldo de toda la región de América Latina y el Caribe. En este sentido Chile dejó constancia de su agradecimiento por las valiosas gestiones que está desarrollando la diplomacia brasileña en favor de esta candidatura, cuya conclusión exitosa contribuirá 
a una mayor presencia de nuestro continente en los organismos internacionales.

31. Hicieron presente su preocupación por el grave problema que constituye la producción, comercialización y consumo de drogas ilícitas, estupefacientes y substancias psicotrópicas, así como el incremento en el tráfico de éstas, destacando las perniciosas consecuencias económicas y sociales que se derivan de estos hechos delictivos. Sobre el particular reiteraron su decidida voluntad de cooperar en la lucha contra el narcotráfico, en el marco de las iniciativas impulsadas por la Organización de Naciones Unidas y por la Organización de los Estados Americanos.

El Ministro de Relaciones Exteriores de la República Federativa del Brasil expresó su especial agradecimiento y el de los miembros de su comitiva, por las atenciones de que fueron objeto por parte del Gobierno y pueblo de Chile, durante su permanencia en el país.

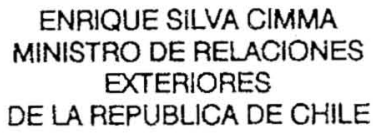

FERNANDO HENRIQUE CARDOSO MINISTRO DE RELACIONES EXTERIORES DE LA REPUBLICA FEDERATIVA DEL. BRASIL 